\title{
Research on the Development Route of International Communication Accesses
}

\author{
Tianpu Yang ${ }^{(凶)}$, Junshi Gao, Xiaoming Chen, Yanchun Guo, and Shuo Sun \\ China Mobile Group Design Institute Co., Ltd., Beijing 10080, China \\ yangtianpu@cmai.chinamobile.com
}

\begin{abstract}
With the implementation of China's Belt and Road Initiative, a new wave of globalization is taking shape, promoting the growth of international service requirements, which requires pre-deployment of international infrastructure. The construction of international communications infrastructure is an important guarantee for China's major international activities, external communication activities, and the normal operation of global and regional economies. International Communication Accesses is an important part of international infrastructure. The development and construction of international accesses is not an intrinsic mode, which involves many factors. It needs long-term planning and local adaptation; it relies on both the policy environment and basic network resources; it should consider both return on investment and convenience services. This document puts forward the future construction route of international communication accesses based on the analysis of factors including macro policies, geographical environments, service requirements, circuit quality improvement, transmission resources, fund support, and security assurance.
\end{abstract}

Keywords: International communication access $\cdot$ Channel access $\cdot$ International submarine cable $\cdot$ Cross-border terrestrial cable

\section{Background}

With the implementation of the Belt and Road Initiative, the new wave of China's globalization is developing continuously, accelerating the interaction and integration between China and other countries. In terms of personnel mobility, the number of Chinese outbound personnel in 2018 soared to a new height. The number of outbound personnel from the Chinese mainland reached 150 million, an increase of $14.5 \%$ over the previous year. By the end of 2018, more than 27,000 Chinese investors have established approximately 43,000 foreign direct investment enterprises in 188 countries (regions), and the investment from China covers more than $80 \%$ of countries (regions). China has set up more than 10,000 international enterprises in countries (regions) along the Belt and Road.

The construction of international communications infrastructure is an important guarantee for China's major international activities, external communication activities, and the normal operation of global and regional economies. Therefore, it is an indispensable prerequisite for responding to China's Belt and Road Initiative, serving Chinese enterprises, and supporting China's globalization. 


\section{Current Situation of International Communication Networks}

International communication networks mainly consist of international communication infrastructure, which includes some points and lines. The points include the international communication accesses inside China and the international nodes outside China. The lines include international submarine cables and cross-border terrestrial cables.

\subsection{International Communication Access}

International communication accesses shall include international communication channel accesses (channel access for short), international communication service accesses (international access for short), and border international communication accesses. International accesses are service transfer points between national communication service networks and international communication service networks. They are mainly used to implement service interconnection and data exchange between the communications networks of operators from the Chinese mainland and the communications networks of foreign operators and operators in Hong Kong, Macao, and Taiwan. The international accesses can effectively shorten optical cable routes, thereby reducing the international circuit delay and improving circuit security. Since international accesses transmit crossborder information, they need to be supervised by government departments. Currently, international accesses in China are mainly constructed by China Telecom, China Mobile, and China Unicom. Up to now, China has set up 11 international accesses distributed in Beijing, Shanghai, Guangzhou, Kunming, Nanning, Urumqi, Hohhot, Fuzhou, Xiamen, Harbin, and Shenzhen.

The services transferred by international accesses include voice, public Internet, data private line, and international Internet transfer services. Since voice and public Internet services are strictly supervised, and the government approval procedure is complex, only Beijing, Shanghai, and Guangzhou are full-service international accesses, and others are data private line or Internet transfer accesses.

Channel accesses are transfer points between national communications transmission channels and international communications transmission channels. Therefore, they are mainly located at international submarine cable landing stations or cross-border terrestrial cable access equipment rooms.

\subsection{International Submarine Cable Construction}

The ocean covers $71 \%$ of the earth's surface, and there is no land between the Oceania, the American continent, and the Eurasia-Africa continent. Only 44 of the nearly 200 countries around the world do not have coastlines. More than $95 \%$ of the global international communication traffic is transmitted through submarine optical cables. After years of construction, submarine optical cables routed from China can be directly connected to North America, Asia, Europe, and Africa, and can be transferred to South America, Africa, and Oceania. China has implemented direct network interconnection with key countries including the United States, Japan, Singapore, and UK. By the end of 2018, five international submarine cable landing stations have been established in the Chinese 
mainland, including Qingdao, Shanghai Nanhui, Shanghai Chongming, Shanghai Lingang, and Shantou, and two submarine cable landing stations connecting to Taiwan have been established in Fuzhou and Xiamen. In addition, Chinese operating enterprises have established international submarine cable landing stations in Tseung Kwan O and Chung Hom Kok of Hong Kong. There are nine international submarine cables landed on the Chinese mainland. China's telecommunications operating enterprises have a bandwidth of over $40 \mathrm{Tbit} / \mathrm{s}$ on submarine cables, and are constructing and planning a batch of projects. In the direction to the US, there are TPE and NCP. In the direction to Southeast Asia, there are APG, SJC, APCN2, EAC, and C2C. In the direction to Europe there are SMW3 and FLAG.

\subsection{Cross-Border Terrestrial Cable Construction}

China borders 14 countries. In addition to international submarine cable construction, cross-border terrestrial cable construction is also indispensable, like the Silk Road Economic Belt and the 21st-century Maritime Silk Road. Cross-border terrestrial cables function as the Silk Road in international communications to connect neighboring countries and lead to Europe and the African continent through neighboring countries. Currently, China has 17 international terrestrial cable border stations, including Horgos, Alashankou, Manzhouli, Pingxiang, and Ruili. It has established cross-border terrestrial cable systems with 12 neighboring countries except Bhutan and Afghanistan, and the system bandwidth exceeds $70 \mathrm{Tbit} / \mathrm{s}$.

\section{Factors Affecting International Access Establishment}

To establish international accesses, the following factors need to be considered: policy environment, geographical environment, necessity of the establishment, and whether the conditions for the establishment are present.

\subsection{Policy Environment}

The policy environment is the major factor to be considered in the establishment of international accesses, because the establishment should be supported by relevant laws and regulations and policies, including country-level macro-policies and local policies.

Country-level macro-policies are divided into two types: relatively broad strategic policies, including the Belt and Road Initiative, continuous reform of international free trade areas, and establishment of the Guangdong-Hong Kong-Macao Greater Bay Area and Xiong' an New Area; closely-related industry policies, including the Outline of the National Information Development Strategy issued by the General Office of the State Council and the Information and Communication Industry Development Plan (20162020) issued by the Ministry of Industry and Information Technology.

Local policies are more specific measures formulated by local governments based on national strategies and related policies, such as the 13th Five-Year Development Plan for the Information and Communications Industry in XX Province. 


\subsection{Geographical Environment}

The geographical environment is an important reference condition for establishing international accesses. The purpose of establishing international accesses is to transfer and supervise international communication services, for which the most important thing is stable communication and easy construction and maintenance. Therefore, when establishing an international access, you need to consider both the geographical location and natural conditions of the selected city, including the risks of natural disasters such as earthquakes and floods. The requirements for geographically selecting the city vary from international access to international access. For example, to establish a global international access, select a location far away from the existing international accesses in Beijing, Shanghai, and Guangzhou, unless the existing international accesses are no longer capable of sustainable development. Regional international accesses should be deployed in regional centers or border provincial cities. In this way, regional international accesses can effectively work with channel accesses to reduce the circuit transfer delay. Therefore, regional international accesses should be deployed based on existing or future international submarine cables and cross-border terrestrial cables.

\subsection{Necessity of International Access Construction}

Establishing international accesses aims to meet international service requirements and improve the quality of international circuits. Service requirements drive the establishment of international accesses. Improving circuit quality is an important way to improve the competitiveness of international communications operators and ensure customer resources.

Service Requirements. International service requirements are the important prerequisite for establishing an international access. In other words, it is necessary to establish an international access only when international service requirements are sufficient. The measurement of international services mainly includes the significance and volume of international services. As to significance, mainly consider whether the regions where the international services pass through have great strategic significance to China. As to service volume, check whether the service volume of the existing international accesses reaches the upper limit, whether the current international services will continue to grow in the next few years, and how the business revenue is.

Quality Improvement. The improvement of international circuit quality includes the reduction of circuit delay and the improvement of circuit security. Under the current technical conditions, the only way to reduce the circuit delay is to reduce the length of optical cable routes. To improve circuit security, optical cables and circuit transmission protection technologies should be used. Setting proper international accesses can effectively reduce international circuit route diversion, thereby reducing the delay. In addition, the reduction of the optical cable route length can also reduce the probability of optical cable interruption and improve circuit security. 


\subsection{Feasibility of International Access Construction}

Transmission Resources. International accesses are mainly used for international circuit transfer and switching. They need to connect to national circuits and outbound circuits. Therefore, the selected international accesses must have abundant national transmission resources and international transmission resources. For national transmission resources, inter-province backbone transmission networks, intra-province backbone transmission networks, and networks with multiple outgoing optical cable routes are preferred. For international transmission resources, regions that have international submarine cables or cross-border terrestrial cables and international transmission resources reaching the Europe, Asia, and North America are preferred. National transmission resources are important carriers of international circuits (consisting of pass-through circuits and cross-border circuits) inside a country. International transmission resources are important guarantee for overseas transmission of international circuits.

Fund Support. The construction of an international access has high requirements on equipment room conditions. Generally, the equipment room must be owned by an enterprise. In addition, the power supply and subsequent communication assurance must meet the highest standards. Therefore, the investment is high. On the other hand, due to the restrictions of national supervision conditions, the international access site needs to reserve the corresponding equipment room location and power supply for the supervision equipment, which increases the enterprise cost. Therefore, fund guarantee is also an important condition for the selection and construction of the international access.

\subsection{Security Assurance Measures}

Generally, the international access provides security assurance based on the highest level in the communications industry. Therefore, during international access construction, a reasonable and effective network and information security assurance system needs to be formulated, dedicated personnel need to be specified for ensuring network and information security, and a complete and feasible network and information security assurance technical solution needs to be formulated.

\section{International Access Establishment Case}

Based on the preceding factors and process, China Mobile chose the Urumqi international access to analyze the process of establishing a regional international access.

\subsection{Environment Factor}

National Policy. In March 2015, the National Development and Reform Commission, Ministry of Foreign Affairs, and Ministry of Commerce of the People's Republic of China jointly released the Vision and Actions on Jointly Building Silk Road Economic Belt and 21st-Century Maritime Silk Road: We should make good use of Xinjiang's 
geographic advantages and its role as a window of westward opening-up to deepen communication and cooperation with Central, South and West Asian countries, make it a key transportation, trade, logistics, culture, science and education center, and a core area on the Silk Road Economic Belt. On land, the Initiative will focus on jointly building a new Eurasian Land Bridge and developing China-Mongolia-Russia, China-Central AsiaWest Asia and China-Indochina Peninsula economic corridors by taking advantage of international transport routes, relying on core cities along the Belt and Road and using key economic industrial parks as cooperation platforms. The China-Pakistan Economic Corridor and the Bangladesh-China-India-Myanmar Economic Corridor are closely related to the Belt and Road Initiative, and therefore require closer cooperation and greater progress. The Ministry of Industry and Information Technology (MIIT) has formulated the Information and Communications Industry Development Plan (2016-2020). The Plan specifies that the China-Russia, China-ASEAN, China-South Asia, and ChinaCentral Asia cross-border terrestrial cable construction should be particularly considered, China will continue the cross-border optical cable construction with neighboring countries, establish direct cross-border optical cables with countries and regions where conditions permit based on business development, expand and optimize the existing cross-border systems if possible, and explore cross-border transfer.

Geographical Conditions. Xinjiang borders Russia, Kazakhstan, Kyrgyzstan, Tajikistan, Pakistan, Mongolia, India, and Afghanistan. The capital city Urumqi has a relatively good economic, humanistic, and natural environment, and can effectively ensure the construction and operation of the international access.

\subsection{Necessity Analysis}

Service Requirements. According to China Mobile's prediction on the service development in Central Asia and Southwest Asia, by 2021, China Mobile will have 2,750 Gbit/s international services passing from Urumqi to Central Asia and Southwest Asia, including 2,490 Gbit/s private line services (including pass-through services) and $260 \mathrm{Gbit} / \mathrm{s}$ Internet transfer services. It mainly provides data private lines for Chinese enterprises' go-global, enterprises that invest in China, and operators and enterprises in Central Asia and Southwest Asia.

Circuit Quality Improvement. Currently, the international data private lines to Central Asia and Southwest Asia are transferred through the Beijing or Guangzhou international access, and then to Central Asia and Southwest Asia through Urumqi/Korla. For services from Xinjiang and surrounding provinces to Central Asia and Southwest Asia, 15 hops are required for one round trip of a circuit, the transmission distance increases by about $6000 \mathrm{~km}$, and the delay increases by about $60 \mathrm{~ms}$, making the cost of circuit construction, operation, and maintenance high (Fig. 1).

After the Urumqi international access is set up, services in the western region can be transmitted to Central Asia and Southwest Asia directly through Urumqi, reducing hops by 15 and the delay by $60 \mathrm{~ms}$, and saving the transmission investment. Services from Central Asia and South Asia to Europe can be transferred directly from Urumqi. 


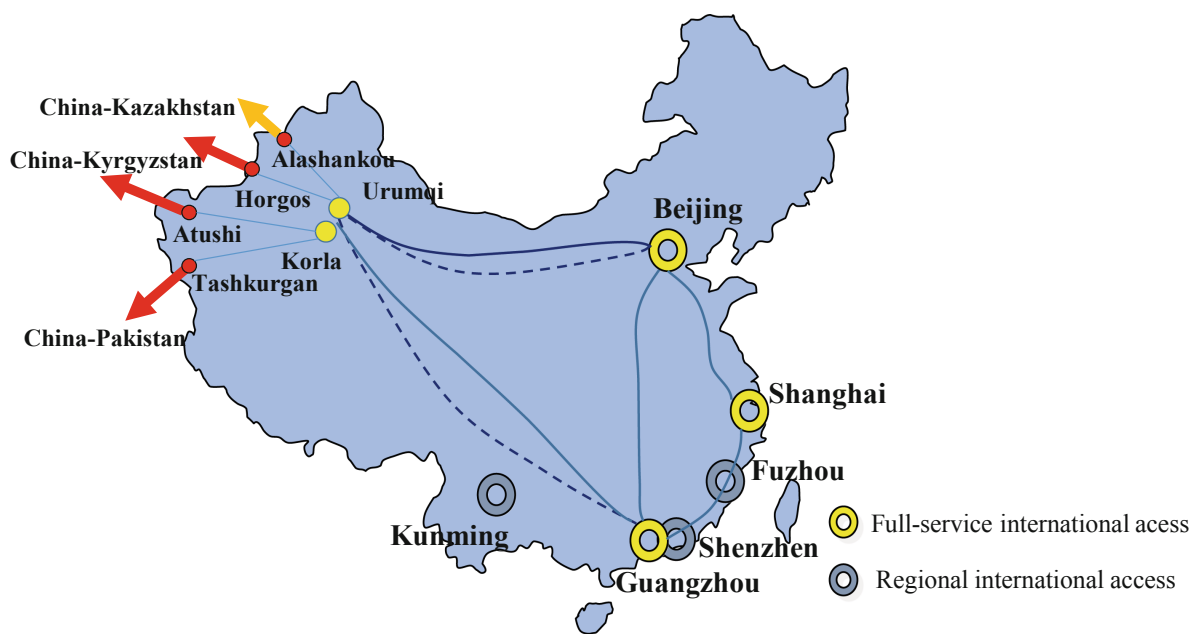

Fig. 1. International circuit route diagram for Central Asia and Southwest Asia

Urumqi has become an important transfer point for international services. This changes the layout of international service accesses in eastern China, southwest China, Beijing, Shanghai, Guangzhou, and Kunming, optimize networks, and improve network security.

\subsection{Construction Feasibility Analysis}

Transmission Resources. Urumqi is the backbone node of China Mobile's international and government/enterprise private transport networks, the backbone node of China Mobile's inter-province backbone transport network, and the backbone node of the provincial backbone network in Xinjiang Uygur Autonomous Region. The city has more than three outgoing optical cable routes. In addition, China Mobile has set up four channel accesses, including Alashankou, Horgos, Atushi, and Tashikuergan in Xinjiang, to connect Kazakhstan, Kyrgyzstan, and Pakistan. In a word, Urumqi has abundant national and international transmission resources and is suitable to set up an international access.

Fund Support. China Mobile is one of the world's top 500 enterprises with strong capital strength and has sufficient funds to set up an international access in Urumqi.

Based on the preceding analysis, the construction of the Urumqi regional international access in meets the policy requirements. The geographical advantages are prominent. The service requirements are urgent. The circuit quality is improved obviously. The existing transmission resources are sufficient. The fund and security can be guaranteed. Therefore, it is feasible to set up the Urumqi international access.

\section{International Access Development Recommendations}

Based on China's international communications development and current international communications infrastructure construction, international accesses should pay attention 
to the balance and capability improvement in future development to promote the overall development of China's economy and society, maintain national network and information security, and serve the Belt and Road Initiative. Many other factors also need to be considered in the development of international accesses. The following are some suggestions proposed based on the current national economy, policy environment, and construction process.

National Economic Belts Provide Prerequisites for International Access Development. With the continuous development of economic globalization, China has continuously launched new economic circles to promote the development of regional economy and foreign trade. Since the Shanghai Free-Trade Zone (Shanghai FTZ) was listed in 2013, the number of China FTZs has reached 18 in six years. In the past six years, China's FTZs have developed from the eastern coast to the western inland and formed a Wild Goose Queue in China's opening-up. The purpose of establishing n FTZs is to build an open economy, further improve trade facilitation and even liberalization, and build core hubs for international trade and logistics, especially in coastal and border provinces of China. For example, Shandong mainly promotes the continuous conversion of old and new kinetic energy, promotes the development of marine economy with high quality, and deepens regional economic cooperation between China, Japan, and South Korea, and promotes the construction of new bases for the opening-up. Guangxi will, by deepening its open cooperation with ASEAN, promoting the construction of a new international land-sea trade channel, and exploring the development and opening-up of border areas, to form an important gateway for the economic integration of the Silk Road Economic Belt and the 21st Century Maritime Silk Road. Yunnan will cooperate with neighboring countries such as Vietnam, Laos, and Myanmar to build an important node that connects South Asia-Southeast Asia channels, and promote the formation of China's radiation center and opening-up frontier oriented to the South Asia and Southeast Asia.

China's establishment of domestic FTZs and continuous construction of new economic zones provide necessary preconditions and future planning direction for the development of international accesses. For example, since the Hainan FTZ was set up, based on Hainan's unique geographical location, submarine cables can be routed from Hainan to the Asia Pacific region, and the Hainan international access can be established to provide a new channel for submarine cables from the western China to the Asia Pacific region, reducing delay and providing communication assurance for foreign enterprises to invest in Hainan. Similarly, Guangxi, Shandong, Zhejiang, Jiangsu, and even the Northeast China are likely to become international accesses.

\section{International Terrestrial and Submarine Cables Promote Balanced Development} of Regional International Accesses. Regional international accesses are supplements to the global full-service international accesses such as Beijing, Shanghai, and Guangzhou. Developing regional international accesses is an effective means to reduce the international circuit delay and improve the circuit security, and can achieve the balanced development of domestic international accesses.

In addition to national macroeconomic factors, the development of regional international accesses needs to be based on the current construction of international submarine cables and cross-border terrestrial cables. The construction of regional international 
accesses is significant only when national transmission resources and cross-border transmission system resources such as terrestrial and submarine cables are available. With the development of China, international submarine cables and cross-border terrestrial cables will be gradually constructed, and new channel accesses will also be gradually set up. At that time, regional international accesses will be set up based on actual service requirements and new network layout.

Take Zhuhai as an example. When the Hong Kong-Zhuhai-Macau Bridge is completed, the cross-bridge optical cables between Zhuhai, Hong Kong, and Macao are also deployed. Therefore, a regional international access can be set up in Zhuhai to cover the western cities of Guangdong. In this way, services from the western cities of Guangdong to Hong Kong and Macao will no longer need to be transferred to Guangzhou or Shenzhen, reducing the average optical cable routes by $200 \mathrm{~km}$ and the optical cable routes on Hong Kong-Macao circuits by $300 \mathrm{~km}$, which improves the quality of international circuits (Fig. 2).

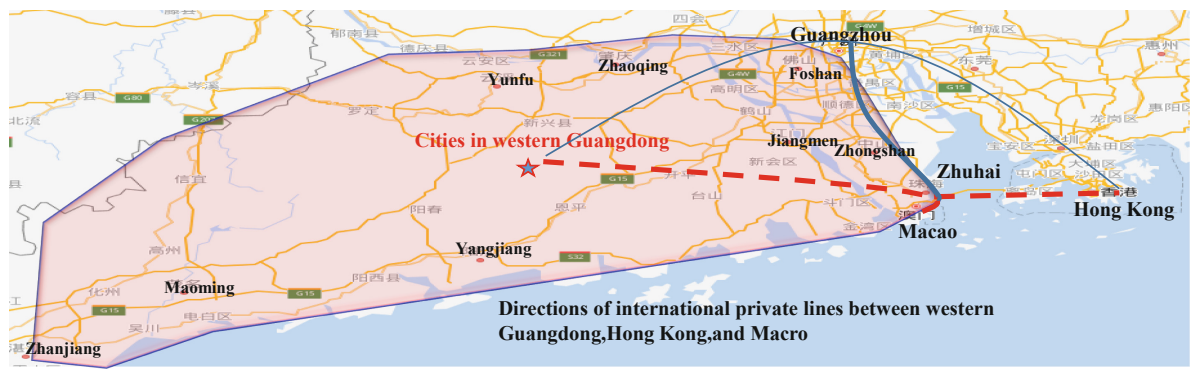

Fig. 2. Directions of the international private lines between western Guangdong, Hong Kong, and Macao

The Capabilities of International Accesses Need to be Improved. Currently, only Beijing, Shanghai, and Guangzhou are full-service international accesses, covering voice, public Internet, and data private line services. Other regional international accesses do not cover voice and public Internet services. With the deepening of reform and opening-up, the demand for international voice and Internet services will increase. Currently, Beijing, Shanghai, and Guangzhou international accesses as a whole have not improved their capability of carrying voice services, and their capability of carrying Internet services lags far behind the growth level of global Internet capacity. This will create a contradiction between demand growth and capability improvement. To solve this problem, on the one hand, the capacity of the existing international accesses can be expanded to improve the transfer and exchange capabilities; on the other hand, the service pressure of the existing international accesses can be shared by adding international accesses or expanding the service coverage of the existing regional international accesses.

As the capital of China, Beijing is the political center. With the migration of other functionalities of Beijing and the existing equipment room conditions of the international access, it is recommended that an international access be set up in the Xiong' an New Area 
as the backup of the Beijing international access to gradually share or carry all services of the Beijing international access. With the continuous increase of Internet traffic, the regional international accesses of coastal or border provinces can be upgraded to increase the public Internet egress capability and reduce the network load in China.

\section{Conclusion}

The development and construction of international accesses is not an intrinsic mode, which involves many factors. It needs long-term planning and local adaptation; it relies on both the policy environment and basic network resources; it should consider both return on investment and convenience services. Therefore, we can put forward a more reasonable and accurate route in the future development of international accesses only by constantly tracking the new situation, new technologies, and new resources at home and abroad.

\section{References}

1. Jie, Z.: Analysis of China's Current International Communications Construction and Development Suggestions, Telecommunications Technology, August 2013

2. China Academy of Information and Communications Technology, White Paper on China International Optical Cable Interconnection (2018), August 2018

Open Access This chapter is licensed under the terms of the Creative Commons Attribution 4.0 International License (http://creativecommons.org/licenses/by/4.0/), which permits use, sharing, adaptation, distribution and reproduction in any medium or format, as long as you give appropriate credit to the original author(s) and the source, provide a link to the Creative Commons license and indicate if changes were made.

The images or other third party material in this chapter are included in the chapter's Creative Commons license, unless indicated otherwise in a credit line to the material. If material is not included in the chapter's Creative Commons license and your intended use is not permitted by statutory regulation or exceeds the permitted use, you will need to obtain permission directly from the copyright holder.

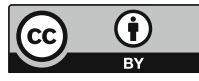

